\section{Changes in Rind Firmness and Cell Wall Polysaccharides during Citrus Fruit Development and Maturation}

\author{
Noboru Muramatsu \\ Department of Breeding, National Institute of Fruit Tree Science, Ministry of \\ Agriculture, Forestry and Fisheries, Tsukuba, Ibaraki 305-8605, Japan
}

Toshio Takahara and Tatsushi Ogata

Department of Citriculture (Kuchinotsu), National Institute of Fruit Tree

Science, Ministry of Agriculture, Forestry and Fisheries, Nagasaki 859-25,

Japan

\section{Kiyohide Kojima \\ Faculty of Agriculture, Niigata University, Niigata, 950-21, Japan}

Additional index words. flavedo, albedo, fruit softening, hydrolysis

\begin{abstract}
Changes in rind firmness and cell wall polysaccharide composition were measured in fruit with a) a soft rind, ('Satsuma' mandarin, Citrus unshiu Marc., cv. Aoshima), and b) a firm rind (hassaku, C. hassaku Hort. ex Tanaka), from August to January of the following year. Rind firmness was similar in both species in August, but hassaku had significantly firmer rind than did mandarin from September to January. Both flavedo and albedo tissues were extracted, and the extracts were hydrolyzed and fractionated to yield four fractions: (hot water, EDTA, hemicellulose, and cellulose). In flavedo tissue, sugar concentration was highest in the cellulose fraction, and lowest in the hemicellulose fraction. The concentration in all fractions decreased as the fruit developed and matured. Although the sugar concentration in the cellulose and EDTA fractions of both species was similar in August, it was significantly higher in both fractions in hassaku than in mandarin in January. The sugar concentration of each fraction from albedo tissue was in the order: cellulose $>$ hemicellulose $>$ hot water $>$ EDTA. The range of variation in cell wall sugars in albedo tissue was smaller than that in flavedo tissue. Chemical name used: ethylenediaminetetraacetic acid (EDTA).
\end{abstract}

In citrus, the relative ease of peeling is one of the most important factors contributing to the convenience of consumption. In fruit with firm rinds, such as hassaku, navel orange $[C$. sinensis (L.) Osbeck], and grapefruit $(C$. paradisi Macf.), the rind must be removed with a knife before eating. In contrast, the rind of soft fruit, such as 'Satsuma' mandarin and 'Clementine' (C. clementina Hort. ex Tanaka), can be easily removed by hand.

Firmness and texture of fruit flesh are very important characteristics during eating. Therefore, many methods have been developed to determine fruit texture. The Magness-Taylor (MT) firmness tester (Magness and Taylor, 1925 ) is small and convenient and is often used to determine optimum harvest date. However, the value measured differs among operators and for the same operator at different times (Abbott et al., 1976). These differences apparently are due to differential rates and depths of penetration of the probe into the

Received for publication 19 May 1997. Accepted for publication 29 July 1998 . We thank Dr. D.J. Huber, Univ. of Florida, Gainesville, for helpful suggestions in preparing this manuscript. The cost of publishing this paper was defrayed in part by the payment of page charges. Under postal regulations, this paper therefore must be hereby marked advertisement solely to indicate this fact. fruit. In the Instron Universal Tester (Instron Corp., Canton, Mass.), the intrusive speed is electrically controlled. In addition, the creep (Mohsenin and Goehlich, 1962) and stress relaxation methods (Kojima et al., 1991; Sakurai and Nevins, 1993) can be applied to analyze the viscous and elastic properties of fruit tissue.

Compared with the number of studies on texture measurement and firmness of fruit flesh, few studies have been conducted on rind firmness. Measurement by the puncture test showed that the softening rate during fruit maturation was reduced by gibberellic acid (GA) treatment (Coggins and Lewis, 1965; McDonald et al., 1987). In these studies, only a single cultivar was analyzed and no comparisons were made among species.

Fruit softening is attributed to the dissolution of cell wall components (Huber, 1983). Sinclair and Joliffe (1961) reported a reduction in pectic substances in citrus rind during fruit development and maturation. Eaks and Sinclair (1980) reported that cellulose and hemicellulose levels were higher in immature than in mature orange peel. Monselise et al. (1976) and Jona et al. (1989) demonstrated an effect of GA on cell wall components of creasing peel. Naohara and Manabe (1994) investigated the changes of pectin during storage of 'Satsuma' mandarin, separately examining fruit rind, membrane, and fruit flesh. In addition, cell wall composition of citrus vesicles and peel was also measured (Braddock, 1983; Yoshida and Ueda, 1984). The relationship between fruit rind firmness and cell wall polysaccharides, however, has not been studied.

The objectives of this study were to determine a) whether firmness of citrus rind can be evaluated by compression and puncture tests, and b) when during fruit development the firmness of the fruit rind becomes measurably different between the soft and firm types. In addition, the relative amount of cell wall polysaccharides, based upon hydrolysis, between firm and soft types of rinds of citrus was also analyzed.

\section{Materials and Methods}

Plantmaterial. Fruit of 15-year-old hassaku and 10-year-old 'Aoshima Satsuma' mandarin trees, planted at the Dept. of Citriculture (Kuchinotsu), National Institute of Fruit Tree Science, were collected once a month from Aug. 1994 to Jan. 1995. At every sampling, three medium-sized fruit of each species were 
selected to measure the firmness and composition of cell wall polysaccharides. Fruit of both species were green and immature in $\mathrm{Au}-$ gust, and then turned orange and matured in January. On the date of fruit sampling, the diameter of 10 fruit was measured at the equator using a slide caliper.

Firmness measurement. To measure firmness rind, a 20-mm-diameter disk was cut with a cork borer. The excised sample was inserted into a $20-\mathrm{mm}$ hole placed in the middle of a rubber sheet ( $4 \mathrm{~cm}$ square and $4 \mathrm{~mm}$ thick). The sample was then placed between two plastic plates ( $4 \mathrm{~cm}$ square) with an 8 -mm hole in the middle. The sample and plates were fixed by two paper clips, and the sample was mounted on the stage of the rheometer (RE3305; Yamaden Co., Tokyo) with flavedo tissue oriented upward (Fig. 1). A cylindrical probe ( $2 \mathrm{~mm}$ in diameter) was used to compress the sample at the rate of $1.0 \mathrm{~mm} \cdot \mathrm{s}^{-1}$. The force for compression and the distance from the surface of the sample were monitored by a computer (PC-9801; NEC, Tokyo) that calculated the maximum force for the probe penetrating the sample. Firmness of each sample was measured three times.

Extraction and fractionation. The rind was fractionated according to the methods reported previously (Muramatsu et al., 1996). The sample was homogenized in $80 \%$ EtOH. After centrifugation, the pellet was treated with $\alpha$ amylase (type I-A, Sigma, St. Louis) and pronase (Actinase; Kaken Kagaku, Tokyo) to remove starch and protein, respectively. The sample was sequentially boiled with water and $50 \mathrm{~mm}$ EDTA (pH 6.5) for 10 and $15 \mathrm{~min}$, respectively, to extract the hot water andEDTA fractions. After the centrifugation, the pellet was immersed in $17.5 \% \mathrm{NaOH}$ overnight at room temparature to yield the hemicellulose fraction. The residue was dried and treated with $72 \% \mathrm{H}_{2} \mathrm{SO}_{4}$ for $1 \mathrm{~h}$ to solubilize the cellulose. Total sugar concentration in each fraction was measured by the phenol-sulfuric acid method (Dubois et al., 1956), using a glucose standard.

\section{Results}

Fruit diameter in both species increased from August to December, then remained constant (Fig. 2A). Since the fruit expansion rate was similar for both species, the difference in fruit diameter between the two species was $\approx 10 \mathrm{~mm}$ in August, and did not change throughout the experimental period.

The rind firmness was almost the same in both species in August, but hassaku had a significantly firmer rind than did 'Satsuma' from September to January (Fig. 2B).

After fractioning the cell wall polysaccharides of the flavedo and albedo tissues, the sugar concentration in each polysaccharide fraction was measured (Figs. 3 and 4). In flavedo tissue, the relative sugar concentrations were: cellulose fraction $>$ hot water fraction $>$ EDTA fractions $>$ the hemicellulose fraction (Fig. 3). Although the concentrations in the cellulose and EDTA fractions were almost the same in August, hassaku had a
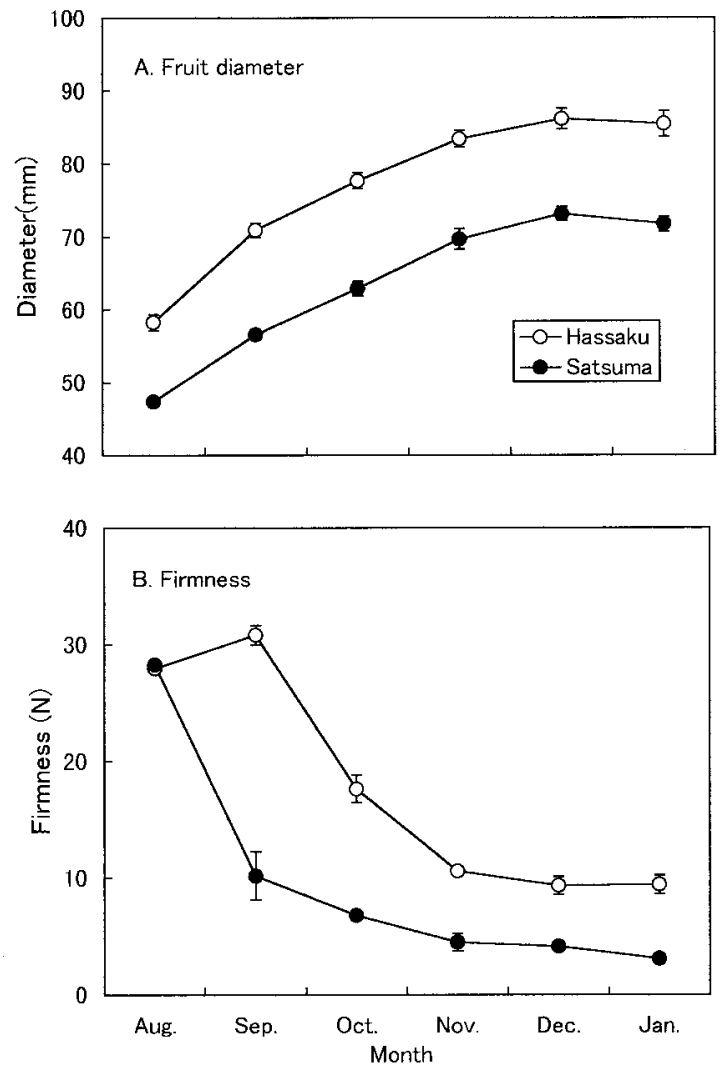

Fig.2. Changes in fruit size and rind firmness during development and maturation of hassaku and 'Satsuma' mandarin. (A) Fruit growth (transverse diameter) and (B) rind firmness measured by the puncture method. Vertical bars represent SE. Means and standard errors are given $(n=10$ in $A$ and $n=3$ in $B$, respectively).

significantly higher sugar concentration than did 'Satsuma' in January. The concentration in the hot water fraction was higher in hassaku than in 'Satsuma' throughout the experimental period. In the hemicellulose fraction, the concentration continued to decrease throughout the experimental period; differences between the two species, however, were not evident.

In albedo tissue, relative sugar concentrations were cellulose fraction $>$ the hot water fraction $>$ hemicellulose fractions $>$ EDTA fraction (Fig. 4). The extent of variation in the albedo tissue was lower than that of flavedo tissue.

\section{Discussion}

Firmness and texture have been evaluated in various fruits using the destructive puncture or compression test (Abbott et al., 1984; Brennan et al., 1970). In these mechanical measurements, sample fixation method, probe shape, and velocity of sample compression are important to accurately measure the sample. In our study, to eliminate the influence of fruit puffiness and fruit flesh, the fruit rind was excised and fixed by two plastic plates. The value measured by this method, however, did not reflect the force to separate fruit flesh and rind. Further study will be required to determine the force for separating peel and flesh.

We previously showed that sugar concentration in the flesh of citrus was highest in the hot water and EDTA fractions, followed by the cellulose and hemicellulose fractions (Muramatsu et al., 1996). Both albedo and flavedo tissues had more sugar in the cellulose fraction, and less in the hot water and EDTA fractions, than did the flesh (Figs. 3 and 4).

Sinclair and Joliffe (1961) measured pectic substances of 'Valencia' oranges during fruit development and maturation, and found that water-soluble pectin decreased with maturation. Eaks and Sinclair (1980) showed that mature orange rind contained lower concentrations of hemicellulose and cellulose than did the immature rind. In our study, also, almost all of the carbohydrate fractions of flavedo tissue decreased as maturation proceeded (Figs. 3 and 4). Our data support earlier reports (Sinclair and Joliffe, 1961), although the pectin data cannot be directly compared to our data of total sugar concentration, which included uronic acid and neutral sugars. Moreover, we showed that hassaku, a firm-rind fruit, contained higher sugar concentrations in the EDTA and cellulose fractions of flavedo tissue than did 'Satsuma' at the mature stage (Fig. 3). Therefore, the rind firmness differences among citrus species may be governed by the sugar concentration in the EDTA and cellulose fractions, although further research using more varieties of citrus must be conducted to test this hypothesis thoroughly.

The separation of fruit flesh from albedo tissue is difficult in hassaku, but comparatively easy in 'Satsuma'. The variation in 

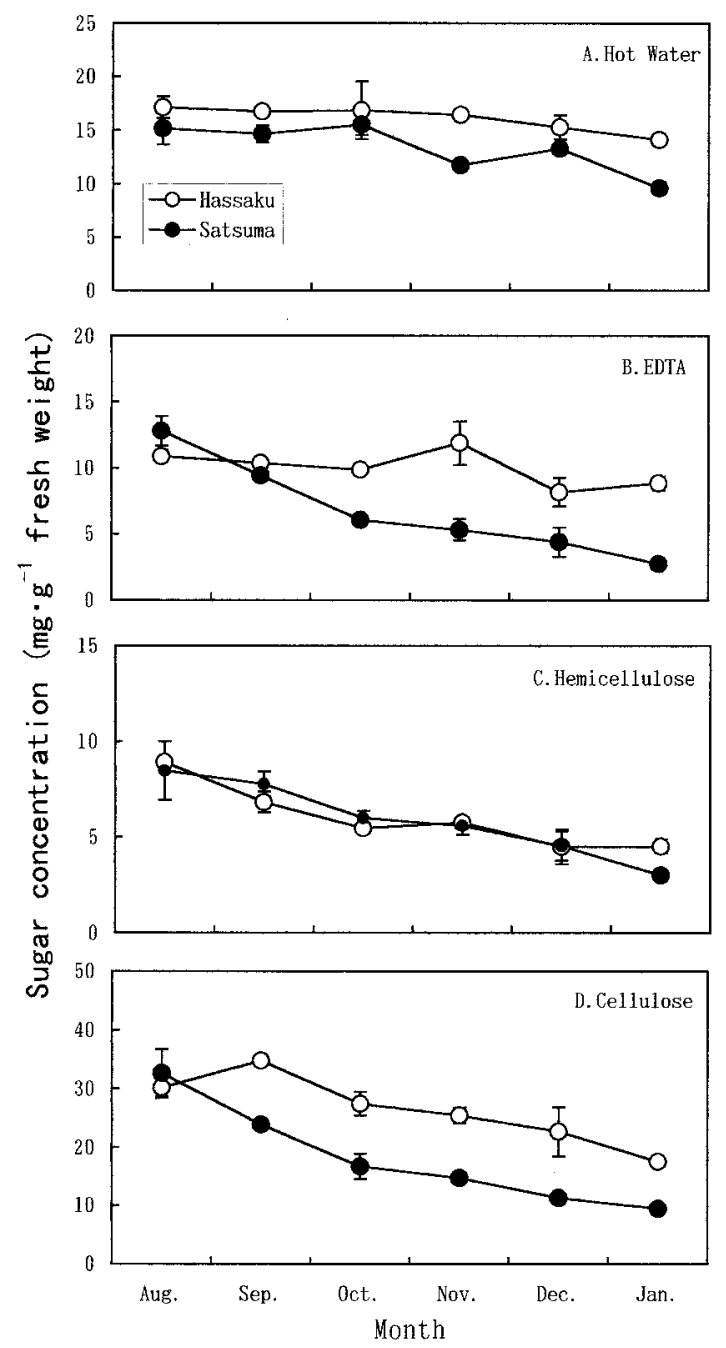

Fig.3. Sugar concentration in $\mathrm{mg} \cdot \mathrm{g}^{-1}$ flavedo tissue fresh weight fractioned into: (A) hot water, (B) EDTA, (C) hemicellulose, and (D) cellulose. Vertical bars represent SE. Means and standard errors are given $(n=3)$.

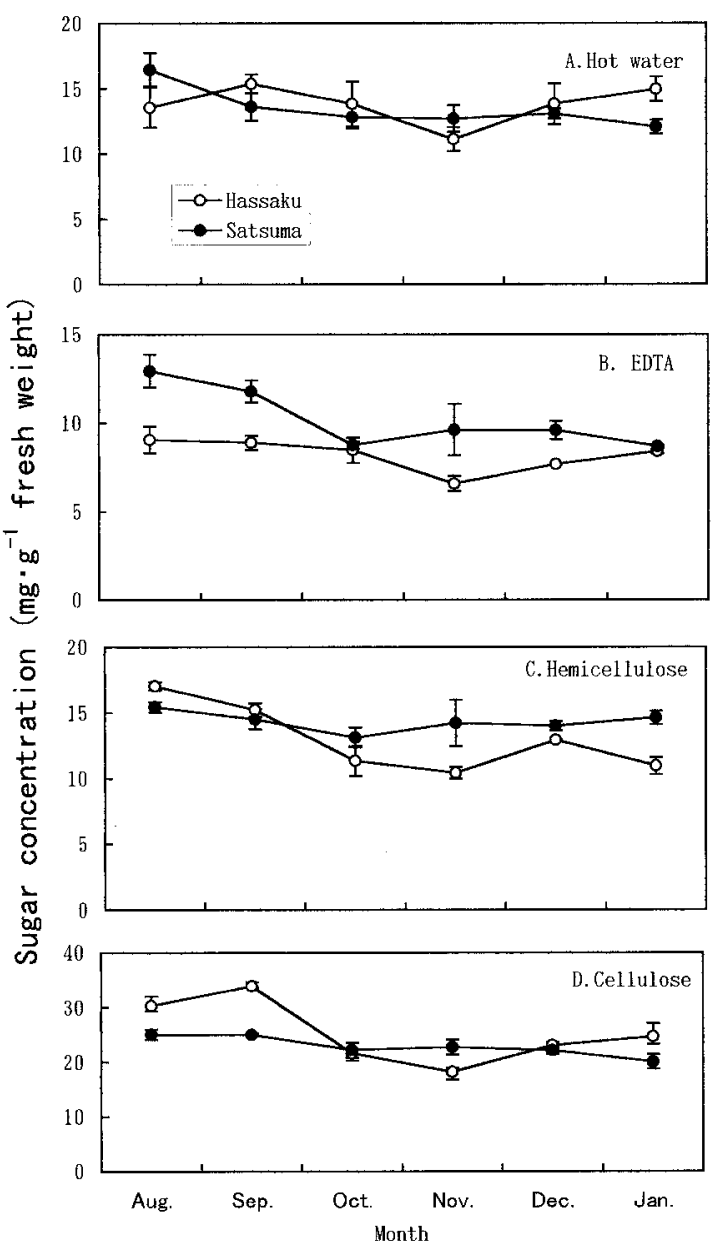

Fig.4. Sugar concentration in $\mathrm{mg} \cdot \mathrm{g}^{-1}$ flavedo tissue fresh weight fractioned into: (A) hot water, (B) EDTA, (C) hemicellulose, and (D) cellulose fractions. Vertical bars represent SE. Means and standard errors are given $(\mathrm{n}=3)$. polysaccharide concentration in albedo tissue was smaller than in flavedo tissue, with no significant differences between the two species during fruit development (Fig. 4). Thus, other factors, e.g., ultrastructure of the tissue, may be related to differences in separating albedo tissue from fruit flesh.

In summary, firmness of citrus rind may be evaluated using excised samples to eliminate the influence of rind puffiness and fruit flesh. The rind firmness was not significantly different between immature soft- and firm-rind fruit, although it became significantly different at maturity. The concentration of cell wall polysaccharides in flavedo tissue decreased with fruit rind softening. Mature fruit with firm rind had higher sugar levels in the EDTA and cellulose fractions of the flavedo tissue than did soft rind fruit.

\section{Literature Cited}

Abbott, J.A. , A.E. Watada, and D.R. Massie. 1976 Effe-gi, Magness-Taylor, and Instron fruit pressure testing devices for apples, peaches and nectarines. J. Amer. Soc. Hort. Sci. 101:698-700.

Abbott, J.A. , A.E. Watada, and D.R. Massie. 1984
Sensory and instrument measurement of apple texture. J. Amer. Soc. Hort. Sci. 109:221-228.

Braddock, R.J. 1983. Utilization of citrus juice vesicle and peel fiber. Food Technol. 37:85-87.

Brennan, J.G., R. Jowitt, and O.A. Mugshi. 1970 Some experiences with the general food Texturometer. J. Texture Studies 1:167-184.

Coggins, C.W. and L.N. Lewis. 1965. Some physical properties of the navel orange rind as related to ripening and gibberellic acid. Proc. Amer. Soc. Hort. Sci. 86:272-279.

Dubois, M., K.A. Gilles, J.K. Hamilton, P.C. Rebers, and F. Smith. 1956. Calorimetric method for determination of sugar and related substances. Anal. Chem. 28:350-356.

Eaks, I.L. and W.B. Sinclair. 1980. Cellulose-hemicellulose fractions in the alcohol-insoluble solid of Valencia orange peel. J. Food Sci. 45:985-988.

Huber, D.J. 1983. The role of cell wall hydrolases in fruit softening. Hort. Rev. 5:169-219.

Jona, R., R. Goren, and M. Marmora. 1989. Effect of gibberellin on cell wall components of creasing peel in mature 'Valencia' Orange. Scientia Hort. 39:105-115.

Kojima, K., N. Sakurai, S. Kuraishi, R. Yamamoto, andD.J. Nevins. 1991. Novel technique for measuring tissue firmness within tomato (Lycopersicon esculentum Mill.) fruit. Plant Physiol. 96:545-550.

Magness, J.R. and G.F. Taylor. 1925. An improved type of pressure tester for the determination of fruit maturity. U.S. Dept. Agr. Circ. 350.
McDonald, R.E. P.E. Shaw, P.D Greany, T.T Hatton, and C.W. Wilson. 1987. Effect of gibberellic acid on certain physical and chemical properties of grapefruit. Trop. Sci. 27:17-22.

Mohsenin, N.N. and H. Goehlich. 1962. Technique for determination of mechanical properties of fruits and vegetables as related to design and development of harvesting and processing machinery. J. Agr. Eng. Res. 7:300-315.

Monselise, S.P., M. Weiser, N. Shafir, R. Goren, and E.E. Goldschmidt. 1976. Creasing of orange peel-Physiology and control. J. Hort. Sci. 51:341-351.

Muramatsu, N., K. Kojima, T. Takahara, and T. Ogata. 1996. Relationship between texture and cell wall polysaccharides of fruit flesh in various species of citrus. HortScience 31:114-116.

Naohara, J. and M. Manabe. 1994. Molecular mass and solubility changes in pectins during storage of Satsuma mandarin fruits (Citrus unshiu Marc.). J. Food Sci. 59:578-580.

Sakurai, N. and D.J. Nevins. 1993. Changes in physical properties and cell wall polysaccharides of tomato (Lycopersicom esculentum Mill.) pericarp tissue. Physiol. Plant 89:681-686.

Sinclair, W.B. and V.A. Joliffe. 1961. Pectic substances of Valencia oranges at different stages of maturity. J. Food Sci. 26:125-130.

Yoshida, Y. and M. Ueda. 1984. Citrus juice waste as a potential source of dietary fibre. J. Jpn. Soc. Hort. Sci. 53:354-361. 